\title{
Acute Monocytic Leukemia
}

National Cancer Institute

\section{Source}

National Cancer Institute. Acute Monocytic Leukemia. NCI Thesaurus. Code C4861.

An acute myeloid leukemia in which the majority of monocytic cells are promonocytes.

(WHO, 2001) 